Article

\title{
Noble Metal-Free Ceria-Zirconia Solid Solutions Templated by Tobacco Materials for Catalytic Oxidation of $\mathrm{CO}$
}

\author{
Donglai Zhu ${ }^{1}$, Deliang Duan ${ }^{2}$, Yi Han ${ }^{1}$, Jiao $\mathrm{He}^{2}$, Yi He ${ }^{2}$, Yongjuan Chen ${ }^{2}$, Wei Zhang ${ }^{1}$, \\ Zhiyin Yan ${ }^{2, *}$, Jiaqiang Wang ${ }^{2, *}$ and Fagui Yuan ${ }^{2}$ \\ 1 Research \& Technology Center of Yunnan Industrial of China Tobacco Industry CO., Ltd., Kunming 650231, \\ China; zhudl@ynzy-tobacco.com (D.Z.); 15288389322@163.com (Y.H.); 13888102860@139.com (W.Z.) \\ 2 Yunnan Provincial Collaborative Innovation Center of Green Chemistry for Lignite Energy, \\ Yunnan Province Engineering Research Center of Photocatalytic Treatment of Industrial Wastewater, \\ The Universities' Center for Photocatalytic Treatment of Pollutants in Yunnan Province, School of Energy, \\ School of Chemical Sciences \& Technology, Yunnan University, Kunming 650091, China; \\ dlduan@ynu.edu.cn (D.D.); hejiao@ynu.edu.cn (J.H.); hecoso@sina.com (Y.H.); \\ chenyongjuan@ynu.edu.cn (Y.C.); yfg1221@163.com (F.Y.) \\ * $\quad$ Correspondence: zhyyan@ynu.edu.cn (Z.Y.); jqwang@ynu.edu.cn (J.W.); Tel.: +86-871-6503-1567 (Z.Y. \& J.W.)
}

Academic Editors: Enrique Rodríguez-Castellón, Agustín Bueno-López and Elisa Moretti Received: 21 July 2016; Accepted: 7 September 2016; Published: 9 September 2016

\begin{abstract}
A series of ceria-zirconia solid solutions were synthesized using tobacco leaves, stems and stem-silks as biotemplates. A combination of physicochemical techniques such as powder X-ray diffraction (XRD), $\mathrm{N}_{2}$ adsorption/desorption measurement, scanning electron microscopy (SEM), and transmission electron microscopy (TEM) were used to characterize the as-synthesized samples. The results show that the morphologies of the templates were well replicated in the obtained ceria-zirconia solid solutions. Catalytic oxidation activities of $\mathrm{CO}$ over the ceria-zirconia solid solutions were then investigated. The catalyst templated by tobacco stem-silk exhibited higher conversion of $\mathrm{CO}$ at lower temperature than that of ceria-zirconia solid solutions templated by tobacco leaves and stems or without templates due to its special morphology. The catalyst even showed similar CO conversion when compared to ceria-zirconia solid solutions doped with $1.0 \mathrm{wt} \%$ noble metals such as $\mathrm{Pt}, \mathrm{Ag}$ and $\mathrm{Au}$. The results highlighted the advantages of using tobacco as biotemplate.
\end{abstract}

Keywords: ceria-zirconia solid solutions; catalytic oxidation; CO; tobacco biotemplates

\section{Introduction}

Catalytic oxidation of $\mathrm{CO}$ at low temperature is becoming increasingly important recently due to its significance in pollution control for automobile exhausts and many industrial processes $[1,2]$. Cerium oxide, which is an important and less expensive rare earth oxide, has been widely investigated for applications to reduce the emissions of $\mathrm{CO}, \mathrm{NO}_{x}$, and hydrocarbons from automobile exhausts [3-5]. However, pure ceria is not very usable because of its relatively low oxygen storage capacity (OSC) and poor thermal stability [6]. To enhance the redox properties and thermal stability of pure ceria, zirconia $\left(\mathrm{ZrO}_{2}\right)$ is often mixed as an additive to form solid solutions of the $\mathrm{Ce}_{1-x} \mathrm{Zr}_{x} \mathrm{O}_{2}$ type $(x \leq 0.5)$. For example, a three way catalyst (TWC) allows simultaneous conversions of $\mathrm{CO}, \mathrm{HCs}$ and $\mathrm{NO}_{x}$ to innocuous compounds. $\mathrm{CeO}_{2}-\mathrm{ZrO}_{2}$ mixed compound, which act as an oxygen storage component to maintain the air to fuel ratio close to stoichiometric is present in the washcoat deposited on either a ceramic or metallic monolith $[7,8]$. A number of methods have been developed for the syntheses of $\mathrm{Ce}_{1-x} \mathrm{Zr}_{x} \mathrm{O}_{2}$ solid solution including solid-state synthesis [9], high-energy milling [10], hydro/solvothermal synthesis [11,12], co-precipitation [13,14], the citrate method [15], inverse 
micelles [16], and template method [17]. $\mathrm{Ce}_{1-x} \mathrm{Zr}_{x} \mathrm{O}_{2}$ solid solutions prepared by different methods showed different activities for CO oxidation $[18,19]$. It seems that $T_{50}$, light-off temperature, the reaction temperature at $50 \% \mathrm{CO}$ conversion, by using ceria-zirconia solid solution without any doping is usually high, and it continues to be a challenge to develop ceria-zirconia solid solution catalyst with lower $T_{50}$.

The OSC, reducibility, and catalytic activity of $\mathrm{Ce}_{1-x} \mathrm{Zr}_{x} \mathrm{O}_{2}$ solutions often depend closely on their microstructures, including crystal size, orientation and morphology [20,21]. The use of templates is an attractive alternative to solve the above-mentioned case concerning the fabrication control and its influence on the interfacial properties. For example, mesoporous phases of ceria- zirconia solid solutions were synthesized using KIT-6 and SBA-15 silica as hard templates [22]. Recently, biotemplating methods have attracted much attention for the preparation of porous inorganic materials, because the approaches to obtain morphology-controllable materials with structural specificity and related unique functions. Furthermore, biological templates are often green and can be harvested in large amounts at low costs so that the method is environment benign and has little requirement for instrumentation [23-25]. However, the application of these biotemplated materials in selective oxidation was still very limited. For example, MFI-type zeolite frameworks with hierarchical porosity and complex architecture templated by Luffa sponge showed catalytic activity for cracking of $n$-hexane with no need for ion-exchange [26]. In our group, rice husks [27], natural rubber latex [28], and reed leaves [29] were used as templates in the preparing of cobalt doped porous titania-silica, mesoporous alumina, and mesoporous silica, which exhibited good catalytic activity for the selective oxidation of 4-methyl pyridine, tetralin, and limonene, respectively. They even offered significantly higher activity than same catalysts prepared by conventional templates such as poly (ethylene oxide)-block-poly (propylene oxide)-block-poly (ethylene oxide) (P123) [28]. However, biotemplate methods have not been used to prepare ceria-zirconia solid solutions so far as we know.

Herein, in the continuation of our work, tobacco leaves, stems and stem-silk were used as templates to synthesize a series of ceria-zirconia solid solutions. They displayed good catalytic properties for $\mathrm{CO}$ oxidation at lower temperature. This work will probably provide a new strategy for the utilization of bio-template in synthesis of ceria-zirconia solid solution.

\section{Results and Discussion}

\subsection{Characterizations}

The XRD patterns of the samples prepared with different $\mathrm{Ce} /(\mathrm{Ce}+\mathrm{Zr})$ molar ratio are shown in Figure 1. All samples exhibit XRD patterns similar to cubic $\mathrm{CeO}_{2}$ (JCPDS card 34-0394) and indicate the formation of stable solid solutions upon the introduction of Zr. Furthermore, all peaks gradually shifted to lower $2 \theta$ values with the increase of $\mathrm{Ce} /(\mathrm{Ce}+\mathrm{Zr})$ molar ratios. This phenomenon suggested that the interplanar spacing and cell parameters became bigger because of the isomorphous substitution of smaller $\mathrm{Zr}^{4+}$ (ionic radius $0.84 \AA$ ) with larger $\mathrm{Ce}^{4+}$ (ionic radius $0.97 \AA$ ) [30].

Nitrogen adsorption/desorption isotherms for the prepared ceria-zirconia solid solutions with different $\mathrm{Ce} /(\mathrm{Ce}+\mathrm{Zr})$ molar ratios are shown in Figures S1-S4, respectively. The isotherms can be classified as being of type IV with $\mathrm{H} 4$ type hysteresis loop, which are characteristic of mesoporous material [31]. Table 1 shows a summary of BET (Brunauer-Emmett-Teller) specific surface area for the prepared ceria-zirconia solid solutions with different $\mathrm{Ce} /(\mathrm{Ce}+\mathrm{Zr})$ molar ratios. It is seen that the surface area of synthesized ceria-zirconia solid solutions are higher than that of pure ceria or pure zirconia. In particular, ceria-zirconia solid solution without any template, CZ40 has highest BET specific surface area $\left(112.08 \mathrm{~m}^{2} / \mathrm{g}\right)$. Interestingly, the biotemplating synthesis process seems not to have changed the BET surface areas of the ceria-zirconia solid solutions to the remarkable extent. 

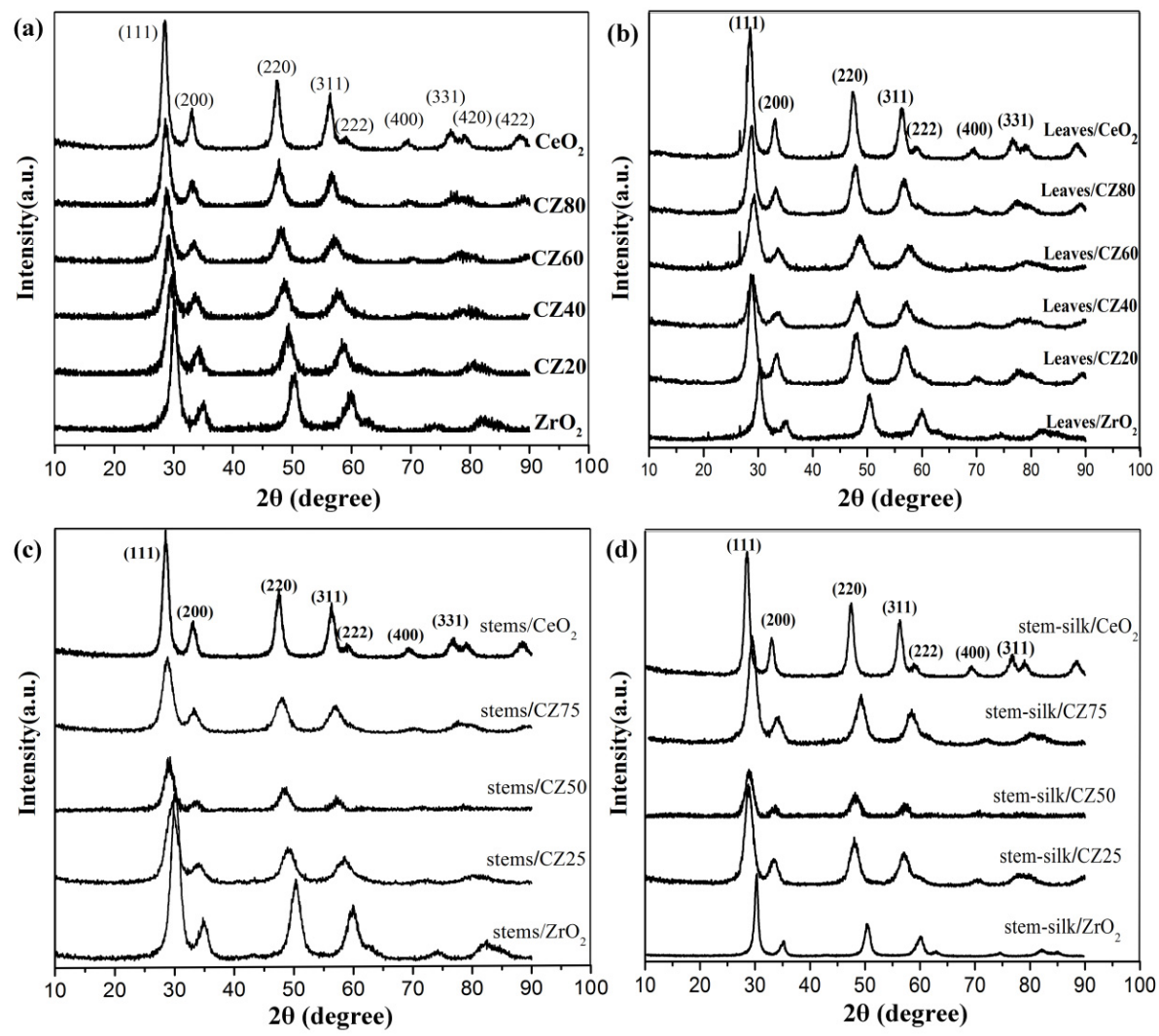

Figure 1. X-ray diffraction (XRD) patterns of the ceria-zirconia solid solutions with different $\mathrm{Ce} /(\mathrm{Ce}+\mathrm{Zr})$ molar ratios (a) using no template; and using: (b) tobacco leaves; (c) tobacco stems; and (d) stem-silk as templates.

Table 1. Summary of BET (Brunauer-Emmett-Teller) specific surface area for the prepared ceria-zirconia solid solutions with different $\mathrm{Ce} /(\mathrm{Ce}+\mathrm{Zr})$ molar ratios.

\begin{tabular}{|c|c|c|c|c|c|c|c|}
\hline Samples & $S_{\text {BET }}\left(\mathrm{m}^{2} \cdot \mathrm{g}^{-1}\right)$ & Samples & $S_{\text {BET }}\left(\mathrm{m}^{2} \cdot \mathrm{g}^{-1}\right)$ & Samples & $S_{\mathrm{BET}}\left(\mathrm{m}^{2} \cdot \mathrm{g}^{-1}\right)$ & Samples & $S_{\mathrm{BET}}\left(\mathrm{m}^{2} \cdot \mathrm{g}^{-1}\right)$ \\
\hline $\mathrm{CeO}_{2}$ & 58.78 & leaves $/ \mathrm{CeO}_{2}$ & 41.37 & stems $/ \mathrm{CeO}_{2}$ & 22.95 & stem-silk/ $/ \mathrm{CeO}_{2}$ & 48.35 \\
\hline CZ80 & 76.55 & leaves/CZ80 & 95.61 & stems/CZ75 & 55.93 & stem-silk/CZ75 & 77.89 \\
\hline CZ60 & 91.80 & leaves/CZ60 & 70.88 & stems/CZ50 & 66.15 & stem-silk/CZ50 & 99.47 \\
\hline $\mathrm{CZ} 40$ & 112.08 & leaves/CZ40 & 66.24 & stems/CZ25 & 42.73 & stem-silk/CZ25 & 75.71 \\
\hline CZ20 & 96.31 & leaves/CZ20 & 60.84 & stems $/ \mathrm{ZrO}_{2}$ & 39.56 & stem-silk/ $\mathrm{ZrO}_{2}$ & 22.49 \\
\hline $\mathrm{ZrO}_{2}$ & 55.03 & leaves $/ \mathrm{ZrO}_{2}$ & 42.02 & - & - & - & - \\
\hline
\end{tabular}

Morphologies and microstructures of these ceria-zirconia solid solutions with 50\% $\mathrm{Ce} /(\mathrm{Ce}+\mathrm{Zr})$ molar ratios using tobacco materials as templates were studied by SEM and TEM. The biotemplates have a significant influence on the morphologies of the synthesized ceria-zirconia solid solutions. Figure 2a shows the SEM image of the tobacco leave templated ceria-zirconia solid solution. It is obvious that the microstructure of leaves/CZ50 is similar to the original leaves structure (Figure S5a).

Besides, some delicate leaf-like structures, such as stoma could be observed in leaves/CZ50 as shown in the magnified SEM image (Figure $2 b$ ). This implied that ceria-zirconia solid solutions using tobacco leaves as templates replicated the original morphology of the tobacco leaves. The microstructure of leaves/CZ50 is also characterized by TEM as illustrated in Figure 2c,d, revealing its sheet structure is composed of fine particles with sizes smaller than $10 \mathrm{~nm}$. Figure $3 a, b$ is the SEM images of stems/CZ50. It is obvious that the stems/CZ50 maintain the tubular structure of tobacco stems (Figure S5b). The stems/CZ50 is composed of fine particles with sizes smaller than $5 \mathrm{~nm}$ according to Figure 3c,d. The SEM images of stem-silk/CZ50 show the tubular structure of tobacco stem-silk-templated ceria-zirconia solid solutions as in Figure 4a,b. The well-aligned porous framework 
is observed in $\mu \mathrm{m}$ scale. Stem-silk/CZ50 really retains the porous configuration of stem-silk faithfully (Figure S5c). The tubular morphology is also characterized by TEM as illustrated in Figure 4c. High magnification TEM image of stem-silk/CZ50 is shown in Figure 4d. These results fully demonstrate that the characteristic morphology of the templates appears to be replicated in the ceria-zirconia solid solutions exactly.
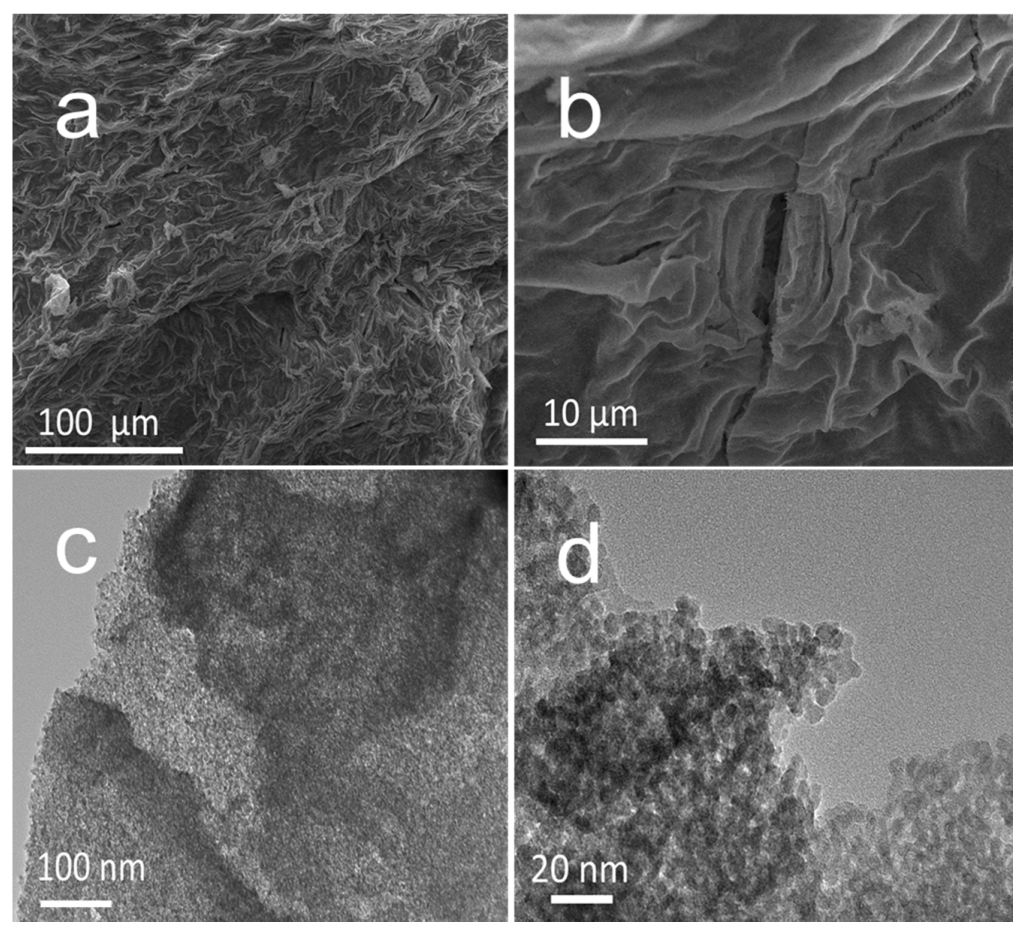

Figure 2. SEM (scanning electron microscopy) (a,b); and TEM (transmission electron microscopy) (c,d) images of leaves/CZ50.

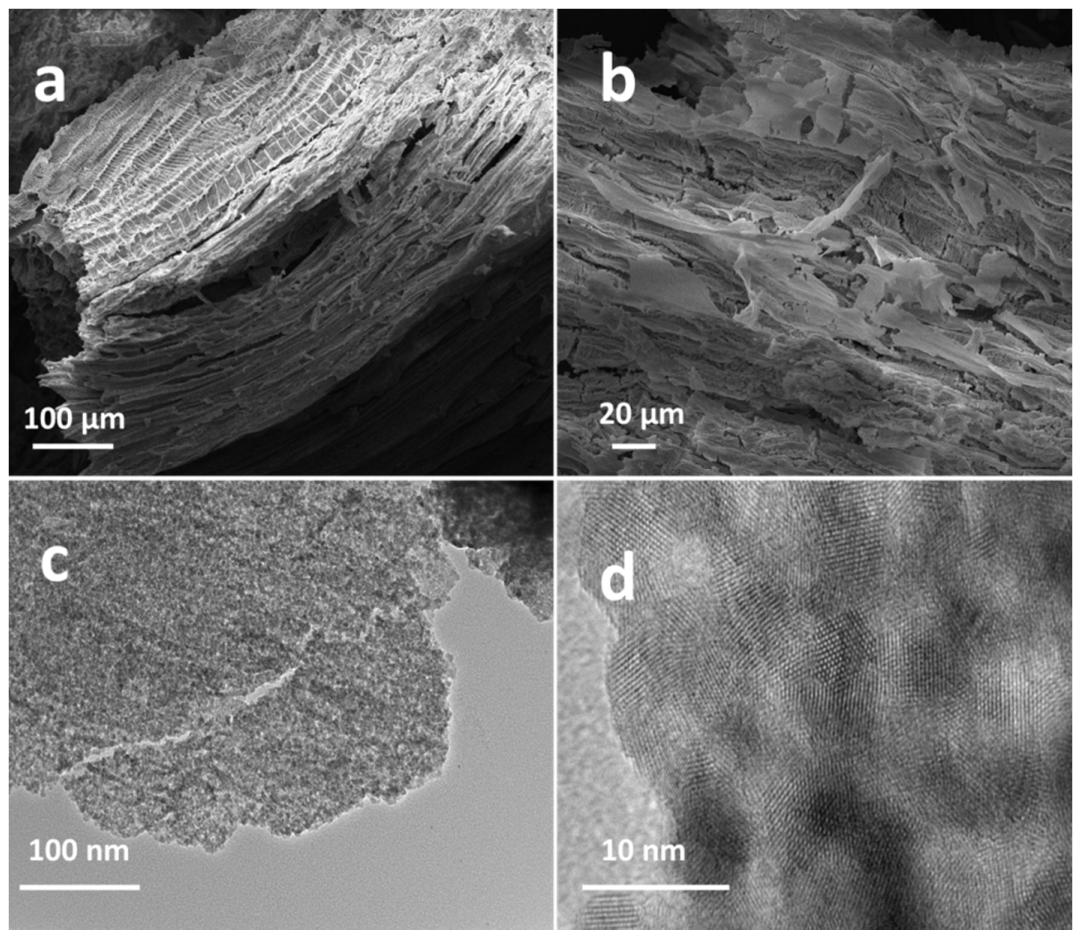

Figure 3. SEM (a,b); and TEM (c,d) images of stems/CZ50. 

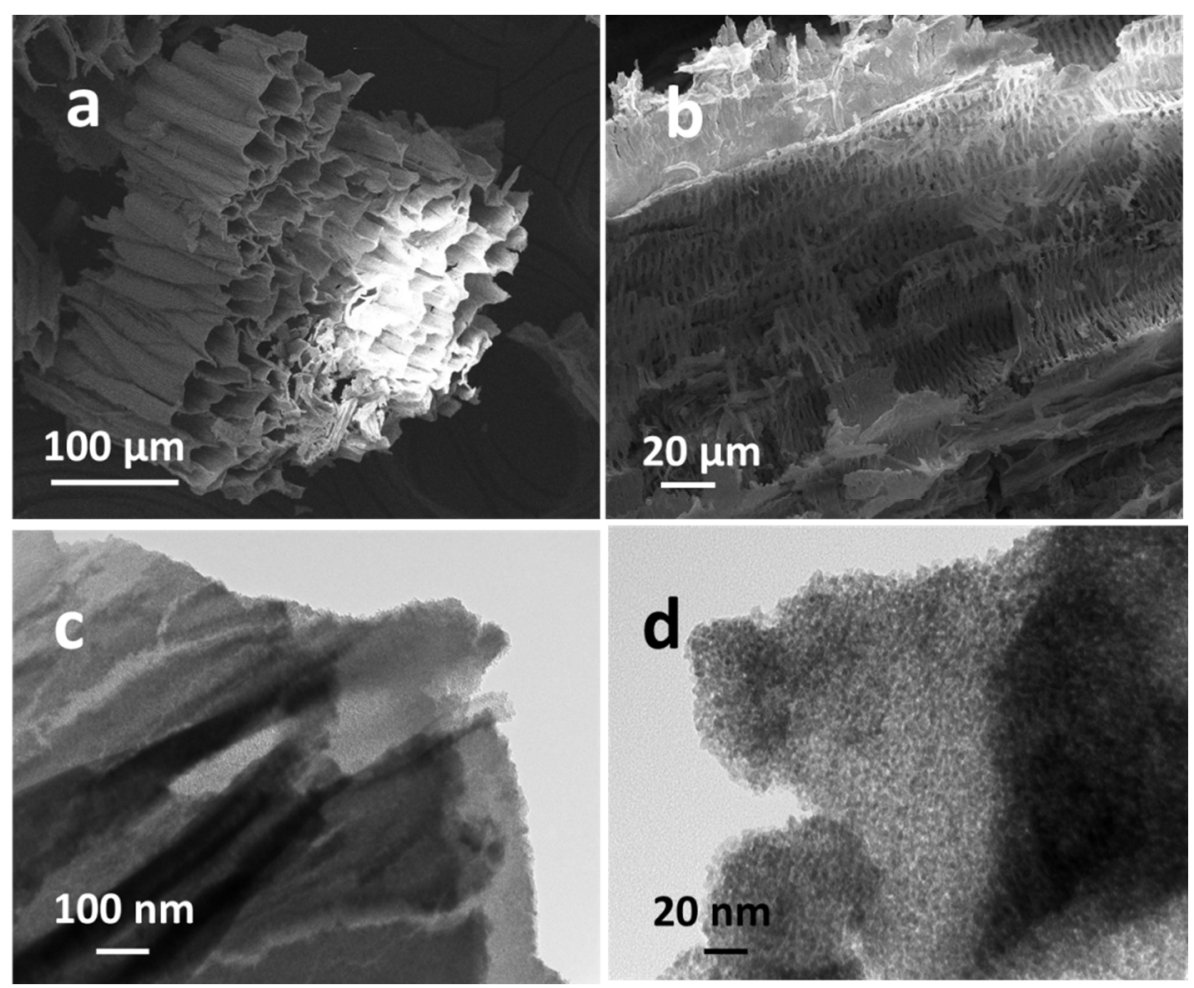

Figure 4. SEM (a,b); and TEM (c,d) images of stem-silk/CZ50.

\subsection{Catalytic Activity}

Figure 5 shows the catalytic performance for $\mathrm{CO}$ oxidation over various ceria-zirconia solid solutions catalysts. $T_{50}$ and $T_{90}$ of all the catalysts are summarized in Table $\mathrm{S} 1$ and Figure 6. Figure 5a shows the catalytic activity profiles of $\mathrm{CO}$ conversion for the ceria-zirconia solid solution samples without templates. CO started conversion above $200{ }^{\circ} \mathrm{C}$ for all catalysts and increased sharply with rising temperature in Figure $5 \mathrm{a} . T_{50}$ and $T_{90}$ (the reaction temperatures at $90 \% \mathrm{CO}$ conversion) were found to decrease with decrease in $\mathrm{Ce} /(\mathrm{Ce}+\mathrm{Zr})$ molar ratios. $T_{50}$ and $T_{90}$ of pure $\mathrm{CeO}_{2}$ are 260 and $300{ }^{\circ} \mathrm{C}$, whereas of $\mathrm{CZ} 20$ are 300 and $370{ }^{\circ} \mathrm{C}$, respectively. The catalytic activity profiles of $\mathrm{CO}$ conversion for the ceria-zirconia solid solution samples templated by tobacco leaves are shown in Figure $5 \mathrm{~b}$. The $\mathrm{CO}$ conversion started above $300^{\circ} \mathrm{C}$ higher than of samples without template. Except leaves/CZ80 the CO oxidation activities decreased with the decrease of $\mathrm{Ce} /(\mathrm{Ce}+\mathrm{Zr})$ molar ratio. $T_{50}$ and $T_{90}$ of leaves $/ C Z 80$ are 515 and $660^{\circ} \mathrm{C}$, whereas of $\mathrm{CZ20}$ are 674 and $776{ }^{\circ} \mathrm{C}$, respectively. Figure $5 \mathrm{c}$ shows the catalytic activity profiles of $\mathrm{CO}$ conversion for the ceria-zirconia solid solution samples templated by tobacco stems. Different from those without templates, templated by leaves and stem-silk, the $\mathrm{Ce} /(\mathrm{Ce}+\mathrm{Zr})$ molar ratios in the stem templated samples had little effect on the $\mathrm{CO}$ oxidation activities. Figure $5 \mathrm{~d}$ shows the catalytic activity profiles of $\mathrm{CO}$ conversion for the ceria-zirconia solid solution samples templated by stem-silk. The catalytic activity of stem-silk templated catalysts appears a different result compare with those discussed above. The $\mathrm{Ce} /(\mathrm{Ce}+\mathrm{Zr})$ molar ratios were either too low or too high led to lower oxidation activity. For example, $T_{50}$ and $T_{90}$ of stem-silk/CZ25 are 300 and $345{ }^{\circ} \mathrm{C}$ respectively. The stem-silk/CZ50 sample exhibited surprisingly high catalytic activity for $\mathrm{CO}$ oxidation at much lower temperatures than all the other samples in this study with $T_{50}$ of $153^{\circ} \mathrm{C}$ and $T_{90}$ of $197^{\circ} \mathrm{C}$. Interestingly, even after loading of $1 \mathrm{wt} \%$ noble metals (Pt, $\mathrm{Ag}$ and $\mathrm{Au}$ ), the CO conversions were not significantly increased compared with stem-silk/CZ50. For example, Pt-stem-silk/CZ50 showed the best catalytic activity, but compared with stem-silk/CZ50, the activity was only slightly increased. It is likely due to the stem-silk/CZ50 itself with high enough activity, there is almost no effect for lower temperature activity, even though Pt was impregnated on these 
supports. On the other hand, noble metal catalysts usually require temperatures above $100{ }^{\circ} \mathrm{C}$ for efficient CO oxidation [32]. Thus, stem-silk/CZ50 ceria-zirconia solid solutions show great promise in the $\mathrm{CO}$ oxidation at low temperature without noble metals. For comparison, $T_{50}$ and $T_{90}$ of all the catalysts are summarized in Figure 6 and Table S1. The following trend was observed in terms of performance: stem-silk/CZ series $>C Z$ series $>$ stems $/ C Z$ series $>$ leaves $/ C Z$ series. It should be pointed out that the catalytic activity has no direct correlation with surface areas. No significant difference was observed from the results of parallel trials and the results were randomly presented here. Moreover, only catalytic oxidation of $\mathrm{CO}$ over the as-prepared ceria-zirconia solid solutions was investigated in this research, but future work will be considered with hydrocarbons, $\mathrm{H}_{2} \mathrm{O}$ (steam), $\mathrm{CO}_{2}$ and oxides of nitrogen containing in the feed to simulate a real combustion exhaust more closely.
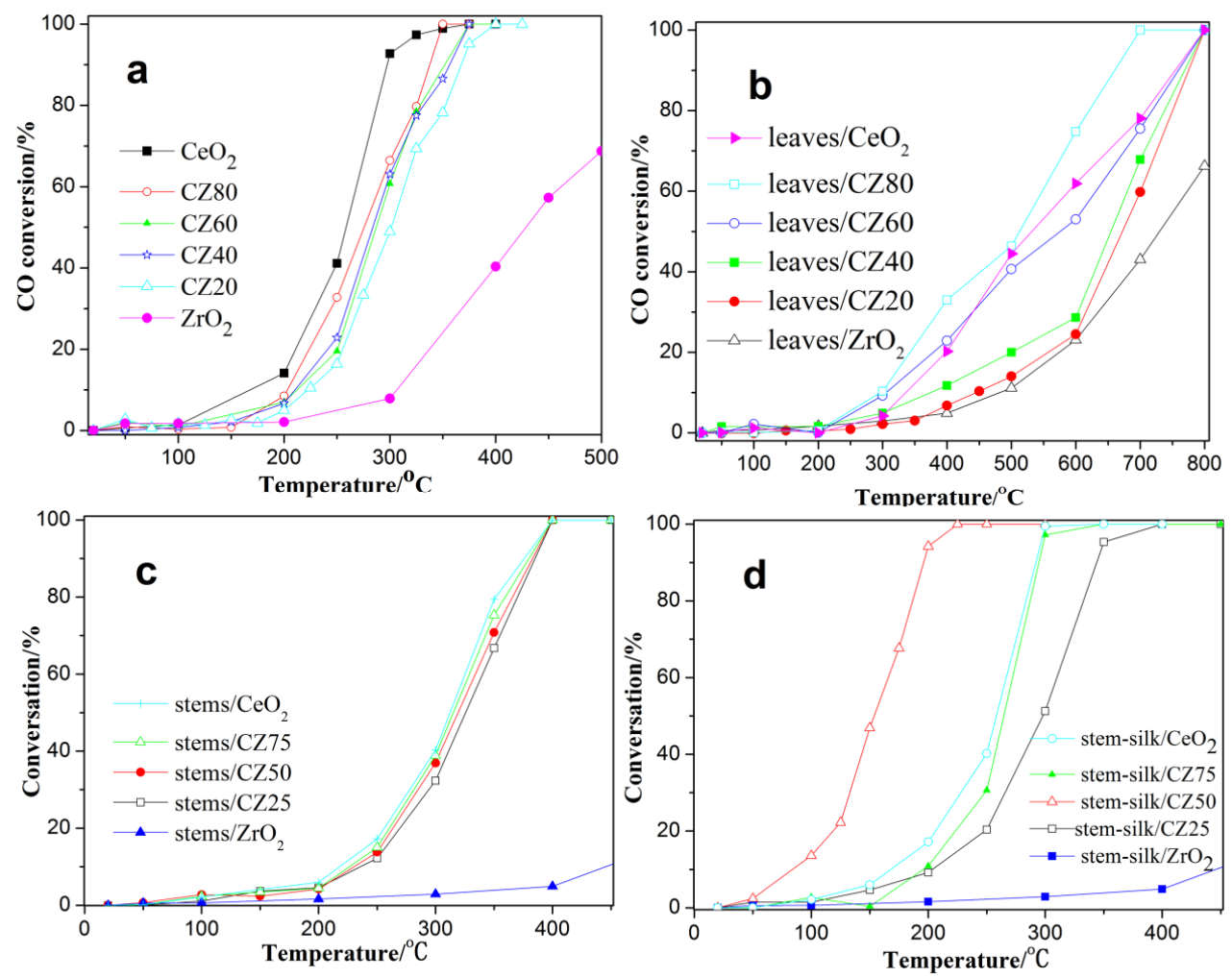

Figure 5. CO conversion as a function of temperature over ceria-zirconia solid solutions (a) without templates; and using: (b) tobacco leaves; (c) tobacco stems; and (d) tobacco stem-silk as templates with different $\mathrm{Ce} /(\mathrm{Ce}+\mathrm{Zr})$ molar ratios.

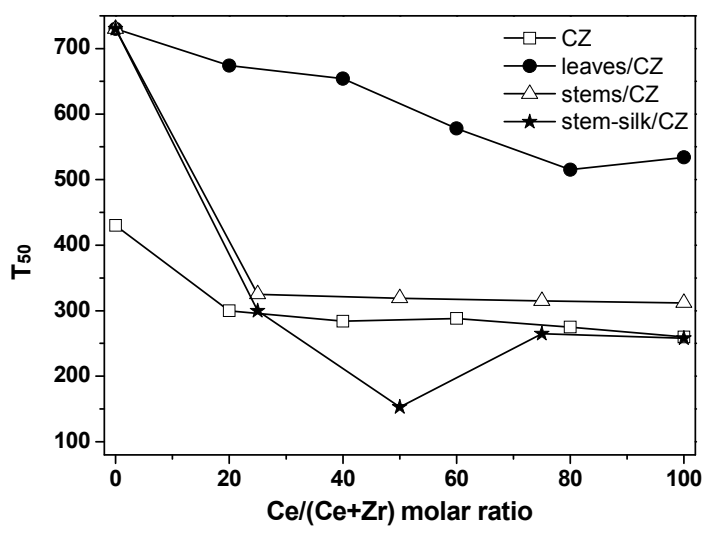

Figure 6. $T_{50}$ of $\mathrm{CO}$ oxidation over ceria-zirconia solid solutions with different $\mathrm{Ce} /(\mathrm{Ce}+\mathrm{Zr})$ molar ratios. 


\subsection{Oxygen Storage Capacity}

Generally speaking, OSC is recognized to improve the catalytic activity [33]. Therefore, OSC was measured by determining the $\mathrm{H}_{2}$ consumption. The $\mathrm{H}_{2}$-TPR (temperature programmed reduction) profiles of ceria-zirconia solid solutions with $50 \% \mathrm{Ce} /(\mathrm{Ce}+\mathrm{Zr})$ molar ratios are shown in Figure 7 . For all samples, there are two broad reduction peaks, the low temperature peaks at $350-415{ }^{\circ} \mathrm{C}$ and the high temperature peaks at $570-630{ }^{\circ} \mathrm{C}$, which can be ascribed to the reduction of $\mathrm{Ce}^{4+}$ (surface $\mathrm{Ce}^{4+}$ and bulk $\mathrm{Ce}^{4+}$ ) [34]. Note that the templates had strong effect on the areas and positions of the reduction peaks of samples. Leaves/CZ50 has the largest peak area and CZ50 exhibits the lowest top temperature. On the basis of TPR profiles, the reducibility and corresponding values of OSC for the ceria-zirconia solid solutions ranked in the following sequence: leaves/CZ50 $(1976 \mu \mathrm{mol} / \mathrm{g})>$ stems $/$ CZ50 $(1173 \mu \mathrm{mol} / \mathrm{g})>$ stem-silk/CZ50 $(1089 \mu \mathrm{mol} / \mathrm{g})>$ CZ50 $(999 \mu \mathrm{mol} / \mathrm{g})$. It is expected that the leaves/CZ50 has fast bulk oxygen mobility and the best reducibility. However, this is not the case: leaves/CZ50, owing to the best reducibility and highest OSC, showed lowest oxidative activity for $\mathrm{CO}$. These results show that the catalytic activity of ceria-zirconia solid solution for $\mathrm{CO}$ oxidation is not ascribed to its surface oxygen reducibility and bulk oxygen mobility. The highest catalytic activity of stem-silk/CZ50 for CO oxidation may be due to its special morphology. Yu and co-workers pointed out that the different morphologies gave rise to various oxygen vacancies and $\mathrm{Ce}^{4+}$ reduction extents of $\mathrm{CeO}_{2}$, thus directly influencing their catalytic performance for the addressed reaction [35]. These results clearly demonstrate the morphology effect of ceria-zirconia solid solutions, regularly tubular morphology are most active. The $\mathrm{Ce}^{4+} / \mathrm{Ce}^{3+}$ redox cycle could be more easily generated on the nanorods due to lower surface reduction energy of ceria on the 110 plane in previous literature [36-38].

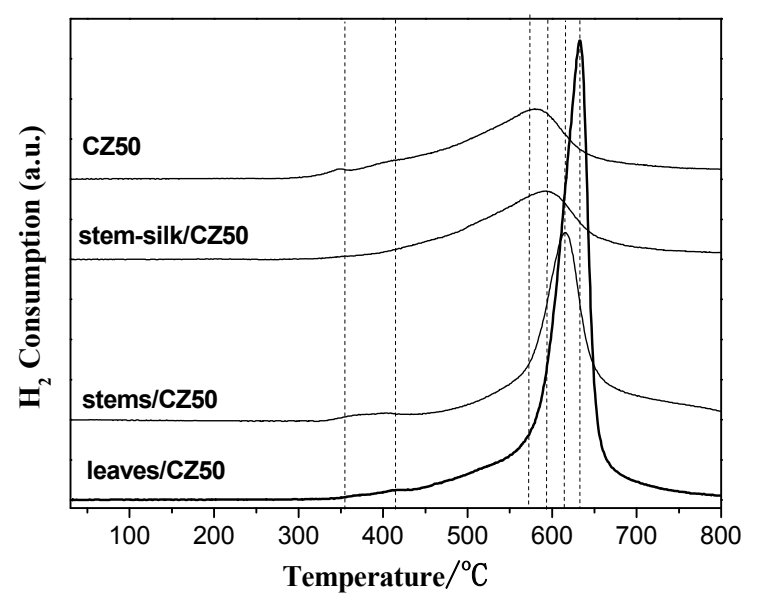

Figure 7. $\mathrm{H}_{2}$-TPR (temperature programmed reduction) profiles of ceria-zirconia solid solutions with $50 \% \mathrm{Ce} /(\mathrm{Ce}+\mathrm{Zr})$ molar ratio.

\section{Materials and Methods}

\subsection{Synthesis}

The ceria-zirconia solid solutions using tobacco materials as templates were synthesized as follows: tobacco materials including tobacco leaves, stems and stem-silk after roasted were sheared to sheets with $1-2 \mathrm{~cm}$ length. The $10 \mathrm{~g}$ templates were firstly treated with $5 \% \mathrm{HCl}$ for $12 \mathrm{~h}$. Then, the templates were dehydrated gradually by ethanol a via a gradual solvent exchange process. The ceria-zirconia solid solutions using tobacco leaves as templates was synthesized by following incipient impregnation method via the reaction of cerium nitrate hexahydrate $\mathrm{Ce}\left(\mathrm{NO}_{3}\right)_{3} \cdot 6 \mathrm{H}_{2} \mathrm{O}$, zirconyl nitrate hexahydrate $\mathrm{ZrO}\left(\mathrm{NO}_{3}\right)_{2} \cdot 6 \mathrm{H}_{2} \mathrm{O}$, and citric acid in aqueous solution. In a typical synthesis of ceria-zirconia solid solutions using tobacco leaves as templates, a $20 \mathrm{~mL}$ aqueous solution containing $0.8598 \mathrm{~g}(0.002 \mathrm{~mol})$ 
of $\mathrm{Ce}\left(\mathrm{NO}_{3}\right)_{3} \cdot 6 \mathrm{H}_{2} \mathrm{O}, 1.8313 \mathrm{~g}(0.008 \mathrm{~mol}) \mathrm{ZrO}\left(\mathrm{NO}_{3}\right)_{2} \cdot 6 \mathrm{H}_{2} \mathrm{O}$ and $4.2028 \mathrm{~g}(0.02 \mathrm{~mol})$ citric acid was added into a closed vessel with immersing the as-treated templates for 3 days. After that, the samples were filtered, dried at $90{ }^{\circ} \mathrm{C}$ for $24 \mathrm{~h}$. Finally, the as-treated samples were calcined at $500{ }^{\circ} \mathrm{C}$ in the air for $6 \mathrm{~h}$ to remove biotemplates. After naturally cooling to room temperature, faint yellow products were obtained. The ceria-zirconia solid solutions samples using tobacco leaves, stems and stem-silk as templates were denoted as leaves $/ C Z x$, stems $/ C Z x$ and stem-silk/CZx ( $x$ represents $\mathrm{Ce} /(\mathrm{Ce}+\mathrm{Zr})$ molar ratio $(\%))$, respectively. A similar procedure was applied in the preparation of conventional ceria-zirconia solid solutions except that in the absence of tobacco materials template was denoted as $\mathrm{CZ} x$ ( $x$ represents $\mathrm{Ce} /(\mathrm{Ce}+\mathrm{Zr}$ ) molar ratio $(\%))$. The noble metal catalysts supported on ceria-zirconia solid solutions were prepared by the conventional impregnation method [39]. The powder of ceria-zirconia solid solutions were impregnated with chloroplatinic acid, silver nitrate and chloroauric acid solution, respectively in order to prepare $\mathrm{Pt}, \mathrm{Ag}$ and $\mathrm{Au}$ doped ceria-zirconia solid solutions. The loading of noble metal ( $\mathrm{Pt}, \mathrm{Ag}$ and $\mathrm{Au}$ ) was set at $1.0 \mathrm{wt} \%$. The mixture was dried at $110{ }^{\circ} \mathrm{C}$ for one day and calcined at $500{ }^{\circ} \mathrm{C}$ for $3 \mathrm{~h}$ in air.

\subsection{Characterizations}

Powder X-ray diffraction (XRD) experiments were conducted on a TTR III spectrometer with $\mathrm{Cu} \mathrm{K} \alpha$ radiation (Rigaku, Tokyo, Japan). Scanning electron microscopy (SEM) images of the samples were taken on a FEI Quanta 200FEG microscope (FEI, Eindhoven, The Netherlands). The transmission electron microscopy (TEM) images were obtained using a JEM-2100 microscope (JEOL, Tokyo, Japan). Pore size distributions, BET surface areas and pore volumes were measured by $\mathrm{N}_{2}$ adsorption/desorption measurements using a Tristar 3020 gas sorption analyzer (Micromeritics, Norcross, GA, USA). $\mathrm{H}_{2}$-TPR experiments were performed with a ChemBET PULSAR TPR/TPD (Quantachrome, Boynton Beach, FL, USA) equipped with thermal conductivity detector (TCD) under 10 vol. $\% \mathrm{H}_{2}$ flow diluted with Ar gas. A 0.05-g catalyst was exposed to a flow of $\mathrm{H}_{2} / \mathrm{Ar}$ mixture. The temperature was ramped from room temperature to $800{ }^{\circ} \mathrm{C}$ at a heating rate of $10{ }^{\circ} \mathrm{C} \cdot \mathrm{min}^{-1}$. After TPR measurement, the values of OSC were quantified by measuring the $\mathrm{H}_{2}$ consumption. The amounts of $\mathrm{H}_{2}$ consumption in the TPR process were calibrated with $\mathrm{CuO}$ reduction as a standard.

\subsection{Catalytic Performance}

Catalytic activity for preferential $\mathrm{CO}$ oxidation was tested using a self-made fixed-bed flow reactor About $100 \mathrm{mg}$ of catalyst powder (60-80 mesh) was packed in a quartz glass U-tube reactor with $8 \mathrm{~mm}$ of inner diameter. The feed gas for the oxidation was about 1 vol. $\% \mathrm{CO}$ balanced with $\mathrm{Ar}$ at a rate of $40 \mathrm{~mL} / \mathrm{min}$. CO oxidation experiments were performed in the temperature range $25-500{ }^{\circ} \mathrm{C}$. The catalysts were heated at the rate of $10{ }^{\circ} \mathrm{C} / \mathrm{min}$ and kept for $5 \mathrm{~min}$ at each reaction temperature before analysis of the product. Measurements were performed under the same reaction conditions. The concentrations of CO in the effluent gas were analyzed on-line by a GC-9790 gas chromatograph (Fuli Instruments, Taizhou, Zhejiang, China) equipped with a thermal conductivity detector (TCD) using $\mathrm{He}$ as carrier gas. The conversion of $\mathrm{CO}$ was calculated from the change in $\mathrm{CO}$ concentration between the inlet and outlet gases.

\section{Conclusions}

A series of ceria-zirconia solid solutions were synthesized using tobacco materials including tobacco leaves, stems and stem-silk as templates. The morphologies of the templates were well replicated in the ceria-zirconia solid solutions exactly. The stem-silk/CZ series showed higher CO oxidation activities. The CO conversions were slightly increased after loading of $1 \mathrm{wt} \%$ noble metal (Pt, Ag and $\mathrm{Au}$ ) when compared to stem-silk/CZ50. The leaves/CZ50, owing to the best reducibility and highest OSC, showed lowest oxidative activity for $\mathrm{CO}$. The catalytic activity of ceria-zirconia solid solution for $\mathrm{CO}$ oxidation is not ascribed to its surface oxygen reducibility and bulk oxygen mobility. The highest catalytic activity of stem-silk / CZ50 for CO oxidation may be due to its special 
morphology. This work will probably provide a new strategy for the utilization of bio-template and synthesis of ceria-zirconia solid solution.

Supplementary Materials: The following are available online at www.mdpi.com/2073-4344/6/9/135/s1, Figure S1: Nitrogen adsorption-desorption isotherms of the ceria-zirconia solid solutions without templates with different $\mathrm{Ce} /(\mathrm{Ce}+\mathrm{Zr})$ molar ratios; Figure S2: Nitrogen adsorption-desorption isotherms of the ceria-zirconia solid solutions with different $\mathrm{Ce} /(\mathrm{Ce}+\mathrm{Zr})$ molar ratios using tobacco leaves as templates; Figure S3: Nitrogen adsorption-desorption isotherms of the ceria-zirconia solid solutions with different $\mathrm{Ce} /(\mathrm{Ce}+\mathrm{Zr})$ molar ratios using tobacco stem as templates; Figure S4: Nitrogen adsorption-desorption isotherms of the ceria-zirconia solid solutions with different $\mathrm{Ce} / \mathrm{Zr}$ ratios using tobacco stem-silk as templates; Figure S5: SEM (scanning electron microscopy) images of tobacco leaves (a), stems (b) and stem-silk (c); Table S1: Summary of $T_{50}$ and $T_{90}$ for the prepared ceria-zirconia solid solutions with different $\mathrm{Ce} /(\mathrm{Ce}+\mathrm{Zr})$ molar ratios.

Acknowledgments: The work was supported by Program for Research \& Technology Center of Yunnan Industrial of China Tobacco Industry CO., Ltd (HYHH2013HX01), National Natural Science Foundation of China (21263027, 21573193, 21367024 and 21403190) and Yunnan Applied Basic Research Projects (2016FA002, and 2016FD009). The authors also thank Program for Innovation Team of Yunnan Province and Innovative Research Team (in Science and Technology) in the Universities of Yunnan Province, Key Laboratory of Advanced Materials for Wastewater Treatment of Kunming and the Key project from the Yunnan Educational Committee (Project ZD2012003) for financial support.

Author Contributions: D.Z., Z.Y., and J.W. conceived and designed the experiments; Y.H. (Yi He) and W.Z. performed the experiments; D.D. and F.Y. analyzed the data; and Y.C., J.H., and Y.H. (Yi Han) wrote the paper.

Conflicts of Interest: The authors declare no conflict of interest.

\section{References}

1. Shelef, M.; McCabe, R.W. Twenty-five years after introduction of automotive catalysts: What next? Catal. Today 2000, 62, 35-50. [CrossRef]

2. Twigg, M.V. Progress and future challenges in controlling automotive exhaust gas emissions. Appl. Catal. B Environ. 2007, 70, 2-15. [CrossRef]

3. Yao, H.C.; Yao, Y.F.Y. Ceria in automotive exhaust catalysts: I. Oxygen storage. J. Catal. 1984, 86, $254-265$. [CrossRef]

4. Steele, B.C.; Heinzel, A. Materials for fuel-cell technologies. Nature 2001, 414, 345-352. [CrossRef] [PubMed]

5. Yin, S.; Minamidate, Y.; Tonouchi, S.; Goto, T.; Dong, Q.; Yamane, H.; Sato, T. Solution synthesis of homogeneous plate-like multifunctional $\mathrm{CeO}_{2}$ particles. RSC Adv. 2012, 2, 5976-5982. [CrossRef]

6. Laachir, A.; Perrichon, V.; Badri, A.; Lamotte, J.; Catherine, E.; Lavalley, J.C.; Fallah, J.E.; Hilaire, L.; Normand, F.L.; Quéméré, E.; et al. Reduction of $\mathrm{CeO}_{2}$ by hydrogen. Magnetic susceptibility and Fourier-transform infrared, ultraviolet and X-ray photoelectron spectroscopy measurements. J. Chem. Soc. Faraday Trans. 1991, 87, 1601-1609. [CrossRef]

7. Zheng, Q.; Farrauto, R.; Deeba, M. Part II: Oxidative Thermal Aging of Pd $/ \mathrm{Al}_{2} \mathrm{O}_{3}$ and $\mathrm{Pd} / \mathrm{Ce}_{x} \mathrm{O}_{y}-\mathrm{ZrO}_{2}$ in Automotive Three Way Catalysts: The Effects of Fuel Shutoff and Attempted Fuel Rich Regeneration. Catalysts 2015, 5, 1797-1814. [CrossRef]

8. Zheng, Q.; Farrauto, R.; Deeba, M.; Valsamakis, I. Part I: A Comparative Thermal Aging Study on the Regenerability of $\mathrm{Rh} / \mathrm{Al}_{2} \mathrm{O}_{3}$ and $\mathrm{Rh} / \mathrm{Ce}_{x} \mathrm{O}_{y}-\mathrm{ZrO}_{2}$ as Model Catalysts for Automotive Three Way Catalysts. Catalysts 2015, 5, 1770-1796. [CrossRef]

9. Varez, A.; Garcia-Gonzalez, E.; Sanz, J. Cation miscibility in $\mathrm{CeO}_{2}-\mathrm{ZrO}_{2}$ oxides with fluorite structure. A combined TEM, SAED and XRD Rietveld analysis. J. Mater. Chem. 2006, 16, 4249-4256. [CrossRef]

10. Trovarelli, A.; Zamar, F.; Llorca, J.; Leitenburg, C.D.; Dolcetti, G.; Kiss, J.T. Nanophase Fluorite-Structured $\mathrm{CeO}_{2}-\mathrm{ZrO}_{2}$ Catalysts Prepared by High-Energy Mechanical Milling. J. Catal. 1997, 169, 490-502. [CrossRef]

11. Wright, C.S.; Walton, R.I.; Thompsett, D.; Fisher, J.; Ashbrook, S.E. One-Step Hydrothermal Synthesis of Nanocrystalline Ceria-Zirconia Mixed Oxides: The Beneficial Effect of Sodium Inclusion on Redox Properties. Adv. Mater. 2007, 19, 4500-4504. [CrossRef]

12. Taniguchi, T.; Watanabe, T.; Matsushita, N.; Yoshimura, M. Hydrothermal Synthesis of Monodisperse $\mathrm{Ce}_{0.5} \mathrm{Zr}_{0.5} \mathrm{O}_{2}$ Metastable Solid Solution Nanocrystals. Eur. J. Inorg. Chem. 2009, 2009, 2054-2057. [CrossRef]

13. Masui, T.; Nakano, K.; Ozaki, T.; Adachi, G.-Y.; Kang, Z.; Eyring, L. Redox Behavior of Ceria-Zirconia Solid Solutions Modified by the Chemical Filing Process. Chem. Mater. 2001, 13, 1834-1840. [CrossRef] 
14. Ouyang, J.; Yang, H. Investigation of the Oxygen Exchange Property and Oxygen Storage Capacity of $\mathrm{Ce}_{x} \mathrm{Zr}_{1-x} \mathrm{O}_{2}$ Nanocrystals. J. Phys. Chem. C 2009, 113, 6921-6928. [CrossRef]

15. Kaspar, J.; Fornasiero, P.; Balducci, G.; Di Monte, R.; Hickey, N.; Sergo, V. Effect of $\mathrm{ZrO}_{2}$ content on textural and structural properties of $\mathrm{CeO}_{2}-\mathrm{ZrO}_{2}$ solid solutions made by citrate complexation route. Inorg. Chim. Acta 2003, 349, 217-226. [CrossRef]

16. An, Y.; Shen, M.; Wang, J. Comparison of the microstructure and oxygen storage capacity modification of $\mathrm{Ce}_{0.67} \mathrm{Zr}_{0.33} \mathrm{O}_{2}$ from $\mathrm{CaO}$ and $\mathrm{MgO}$ doping. J. Alloys Compd. 2007, 441, 305-310. [CrossRef]

17. Ghom, S.A.; Zamani, C.; Nazarpour, S.; Andreu, T.; Morante, J.R. Oxygen sensing with mesoporous ceria-zirconia solid solutions. Sens. Actuators B Chem. 2009, 140, 216-221. [CrossRef]

18. Chen, W.T.; Chen, K.B.; Wang, M.F.; Weng, S.F.; Lee, C.S.; Lin, M.C. Enhanced catalytic activity of $\mathrm{Ce}_{1-x} \mathrm{M}_{x} \mathrm{O}_{2}$ $(\mathrm{M}=\mathrm{Ti}, \mathrm{Zr}$, and Hf) solid solution with controlled morphologies. Chem. Commun. 2010, 46, 3286-3288. [CrossRef] [PubMed]

19. Li, J.; Liu, X.; Zhan, W.; Guo, Y.; Guo, Y.; Lu, G. Preparation of high oxygen storage capacity and thermally stable ceria-zirconia solid solution. Catal. Sci. Technol. 2016, 6, 897-907. [CrossRef]

20. Thammachart, M.; Meeyoo, V.; Risksomboon, T.; Osuwan, S. Catalytic activity of $\mathrm{CeO}_{2}-\mathrm{ZrO}_{2}$ mixed oxide catalysts prepared via sol-gel technique: CO oxidation. Catal. Today 2001, 68, 53-61. [CrossRef]

21. Chen, G.; Rosei, F.; Ma, D. Template engaged synthesis of hollow ceria-based composites. Nanoscale 2015, 7, 5578-5591. [CrossRef] [PubMed]

22. Abdollahzadeh-Ghom, S.; Zamani, C.; Andreu, T.; Epifani, M.; Morante, J.R. Improvement of oxygen storage capacity using mesoporous ceria-zirconia solid solutions. Appl. Catal. B Environ. 2011, 108-109, 32-38. [CrossRef]

23. Anderson, M.W.; Holmes, S.M.; Hanif, N.; Cundy, C.S. Hierarchical Pore Structures through Diatom Zeolitization. Angew. Chem. Int. Ed. 2000, 39, 2707-2710. [CrossRef]

24. Fan, T.-X.; Chow, S.-K.; Zhang, D. Biomorphic mineralization: From biology to materials. Prog. Mater. Sci. 2009, 54, 542-659. [CrossRef]

25. Miao, Y.; Zhai, Z.; He, J.; Li, B.; Li, J.; Wang, J. Synthesis, characterizations and photocatalytic studies of mesoporous titania prepared by using four plant skins as templates. Mater. Sci. Eng. C 2010, 30, 839-846. [CrossRef]

26. Zampieri, A.; Mabande, G.T.P.; Selvam, T.; Schwieger, W.; Rudolph, A.; Hermann, R.; Sieber, H.; Greil, P. Biotemplating of Luffa cylindrica sponges to self-supporting hierarchical zeolite macrostructures for bio-inspired structured catalytic reactors. Mater. Sci. Eng. C 2006, 26, 130-135. [CrossRef]

27. Zhai, Z.; Miao, Y.; Sun, Q.; Tao, H.; Wang, W.; Wang, J. Synthesis of Cobalt Doped Porous Titania-Silica Prepared by Using the Rice Husks as Both Silicon Source and Template and its Catalytic Oxidation of 4-Methyl Pyridine. Catal. Lett. 2009, 131, 538-544. [CrossRef]

28. Ma, Y.; Zeng, M.; He, J.; Duan, L.; Wang, J.; Li, J.; Wang, J. Syntheses and characterizations of cobalt doped mesoporous alumina prepared using natural rubber latex as template and its catalytic oxidation of tetralin to tetralone. Appl. Catal. A Gen. 2011, 396, 123-128. [CrossRef]

29. Li, J.; Li, Z.; Zi, G.; Yao, Z.; Luo, Z.; Wang, Y.; Xue, D.; Wang, B.; Wang, J. Synthesis, characterizations and catalytic allylic oxidation of limonene to carvone of cobalt doped mesoporous silica templated by reed leaves. Catal. Commun. 2015, 59, 233-237. [CrossRef]

30. Xu, L.; Song, H.; Chou, L. Mesoporous nanocrystalline ceria-zirconia solid solutions supported nickel based catalysts for $\mathrm{CO}_{2}$ reforming of $\mathrm{CH}_{4}$. Int. J. Hydrog. Energy 2012, 37, 18001-18020. [CrossRef]

31. Sing, K.S. Reporting physisorption data for gas/solid systems with special reference to the determination of surface area and porosity (Recommendations 1984). Pure Appl. Chem. 1985, 57, 603-619. [CrossRef]

32. Oh, S.; Hoflund, G. Low-temperature catalytic carbon monoxide oxidation over hydrous and anhydrous palladium oxide powders. J. Catal. 2007, 245, 35-44. [CrossRef]

33. Fally, F.; Perrichon, V.; Vidal, H.; Kaspar, J.; Blanco, G.; Pintado, J.M.; Bernal, S.; Colon, G.; Daturi, M.; Lavalley, J.C. Modification of the oxygen storage capacity of $\mathrm{CeO}_{2}-\mathrm{ZrO}_{2}$ mixed oxides after redox cycling aging. Catal. Today 2000, 59, 373-386. [CrossRef]

34. Fornasiero, P.; Balducci, G.; di Monte, R.; Kašpar, J.; Sergo, V.; Gubitosa, G.; Ferrero, A.; Graziani, M. Modification of the Redox Behaviour of $\mathrm{CeO}_{2}$ Induced by Structural Doping with $\mathrm{ZrO}_{2}$. J. Catal. 1996, 164, 173-183. [CrossRef] 
35. Ho, C.; Yu, J.C.; Kwong, T.; Mak, A.C.; Lai, S. Morphology-Controllable Synthesis of Mesoporous CeO 2 Nano- and Microstructures. Chem. Mater. 2005, 17, 4514-4522. [CrossRef]

36. Zhou, K.; Wang, X.; Sun, X.; Peng, Q.; Li, Y. Enhanced catalytic activity of ceria nanorods from well-defined reactive crystal planes. J. Catal. 2005, 229, 206-212. [CrossRef]

37. Yang, Z.; Fu, Z.; Wei, Y.; Hermansson, K. The electronic and reduction properties of $\mathrm{Ce}_{0.75} \mathrm{Zr}_{0.25} \mathrm{O}_{2}(110)$. Chem. Phys. Lett. 2008, 450, 286-291. [CrossRef]

38. Chen, A.; Zhou, Y.; Ta, N.; Li, Y.; Shen, W. Redox properties and catalytic performance of ceria-zirconia nanorods. Catal. Sci. Technol. 2015, 5, 4184-4192. [CrossRef]

39. Kamiuchi, N.; Haneda, M.; Ozawa, M. Enhancement of OSC property of Zr rich ceria-zirconia by loading a small amount of platinum. Catal. Today 2014, 232, 179-184. [CrossRef]

(C) 2016 by the authors; licensee MDPI, Basel, Switzerland. This article is an open access article distributed under the terms and conditions of the Creative Commons Attribution (CC-BY) license (http://creativecommons.org/licenses/by/4.0/). 